mountain hypoxemia can be decreased to a great extent. Key words: altitude; ballistics; gangrene; gunshots; helicopters; hypoxemia; hypoxia; oxygen; penetration; prehospital; saturation; transportation; wounds

Prehosp Disast Med 2001;16(2):s90.

\section{Treatment of Shock Resulting from Abortion Using Misoprostol: A Case Report Zhang Lin; et al.}

Taian Taishan District Family-Planning Service Station, Shandong, PEOPLE'S REPUBLIC OF CHINA

A woman who was five weeks pregnant ingested mifeiston with misoprostol for induction of an abortion. She developed shock 10 minutes after taking three pieces of misoprostol. By way of a series of emergency treatments, the patient improved from her critical condition and an abortion followed. We concluded that the medicine that induced the shock was misoprostol and not the others. In clinical settings where abortions are medicine-induced, it is important to monitor the patient closely after dosing in order to avoid this complication.

Key words: abortion, complications; induction; medicine; mifeiston; misoprostol; shock; treatment

Prebosp Disast Med 2001;16(2):s90.

\section{Development and Analysis of a Peacetime and Wartime Portable Ambulance Zbang Wencai; Zuo Fengting}

No. 252 Hospital of PLA, Hebei Baoding, PEOPLE'S REPUBLIC OF CHINA

This paper mainly concerns a special portable ambulance used in peacetime or wartime that can be assembled using some new systems. The purpose, necessity, feasibility, and operation instructions are discussed in detail. The stretcher not only can alleviate the suffering of the patients whose bed must be exchanged at the time of medical treatment, but also reduces the labor intensity of medical personnel. Specifically, used as an unsophisticated, operation table or an examination bed in wartime, or, in exceptional cases such as fighting against natural calamities, it may be used in urgent operations and early surgical treatment. In short, it may be useful in many fields.

Key words: ambulance, portable; examination bed; stretcher; surgical bed

Prehosp Disast Med 2001;16(2):s90.

\section{The Management of Mass Casualties of Serious Earthquakes in China Yi Bin Zhang}

Fu Dan University, Zhong Shan Hospital, Shanghai, PEOPLES REPUBLIC OF CHINA

Since 1950, China has endured 11 serious (Richter magnitude $>7$ ) earthquakes. Statistics indicate that more than 280,000 people died, and approximately $1,000,000 \mathrm{~m} 2$ of houses were destroyed. Recently, we rendered first aid to those injured in the most serious earthquake in the TongShan area of Northern China, where 242,000 inhabitants were killed and 164,000 were either slightly or seriously wounded. Almost all of the buildings in the city, high and low, were demolished. These buildings certainly included water and electricity supply systems and medical organizations.

At the time, there were 218 emergency medical support groups from all over the country with memberships of 19,772 medical practitioners. They received 145,800 wounded persons. Among them, 63,400 were serious and 29,600 were in critical condition. Both had to receive emergency care. Statistics showed that $92 \%$ of wounded were treated with debridement, and others were separated into different categories with different treatments as following: $3.9 \%$ were treated with laparotomy; $0.13 \%$ with intestinal repair; $0.26 \%$ with splenectomy; $1.5 \%$ with fracture reduction; $0.2 \%$ with amputation; $0.13 \%$ with laminectomy; and 1.14\% with other operation. From 28 July to August 1996, altogether 15,351 wounded persons were transported to hospitals in other places by air and 72,818 to other places by train.

Key words: deaths; debridement; earthquakes; emergency; injured; Japan; laparotomy; surgery; Tong-Shan Prebosp Disast Med 2001;16(2):s90.

\section{Effects of Cytokine Gene Therapy on Prolonging Survival Time of Allografted Skin Zheng Jianghong; Gu Caizhi; Lin Zbibao; et al.} Department of Burn and Plastic Surgery, General Hospital of Urumqi, Urumqi, PEOPLE'S REPUBLIC OF CHINA

Objective: To explore the role of cytokine gene therapy on prolonging the survival time of allografted skin after scalding in a murine model.

Methods: The Interleukin-10 (IL-10) gene was employed as therapeutic objective gene and fibroblast was used as a carrier cell. The gene transcription technique was adopted to establish an experimental murine model in which fibroblast-mediated gene therapy was used to prolong the allografted skin survival time after scalding. IL-10 was transferred into fibroblastocyte (NIH3T3) by reverse transcriptive virus vector. The mice were grafted with alloskin after scalding. In addition, collagen capsulized NIH3T3IL-10 cells were implanted intraperitoneally into the mice so as to observe its influence on allografted skin survival time and on the changes of their main internal organs.

Results: Cytokine gene therapy prolonged the survival time of allografted skin $(p<0.01)$ without any evident detrimental effect on the internal organs.

Conclusion: These results indicate that skin allograft rejection could be inhibited and the survival time prolonged with the implantation of the fibroblastocyte-transferred IL-10 gene.

Key words: allograft; fibroblastocyte; gene; interleukin-10; scalding; skin; survival time

Prebosp Disast Med 2001;16(2):s90. 